\title{
Investigating the Effect of a Sonic Restrictor in the Intake of an Engine
}

\author{
Maura Gallarotti Alessandro Picarelli Mike Dempsey \\ Claytex Services Ltd., Edmund House, Rugby Road, Leamington Spa, CV32 6EL, UK \\ \{maura.gallarotti, alessandro.picarelli, mike.dempsey\} @claytex.com
}

\begin{abstract}
The air induction system is one of the engine subsystems that most influences fuel efficiency and power generation, especially in restricted race engine applications.

In this paper, the quasi-1D model of a sonic restrictor is presented, together with its integration in an engine model, in order to investigate the behaviour of the engine power and torque when the choked condition is reached.

The study shows how power and torque curves are affected when a sonic restrictor is installed within the intake system and outlines the need of detailed simulations in a restricted engine development process, to avoid steep engine power reductions at high speeds.
\end{abstract}

Keywords: sonic restrictor, choked flow, engine, MVEM, intake manifold.

\section{Introduction}

The development of high-fidelity predictive models of vehicle engines is one of the main objectives of powertrain simulation engineers. Dymola is a convenient software for vehicle and engine modelling, since the underlying Modelica language is suited to complex multi-domain systems.

However, as Dymola is mainly limited to $0 \mathrm{D}-1 \mathrm{D}$ thermofluid systems, engineers can face some intricacies in modelling the more complex flows happening in engines. To get better results, CFD simulations can be performed, but often at the cost of losing the integration with the mechanical part of the model and losing any real-time simulation capability.

This paper shows that although Dymola is not a CFD code, it can handle the inherent non-linearities of the nozzle flow that arise in the transition from the subcritical to the choked state.

A sonic restrictor is a converging-diverging nozzle installed in the intake system in order to limit the maximum power output of the engine by limiting the mass flow of air flowing into the cylinders.

In situations where the engine would require a higher mass flow than the one allowed by the nozzle, the constraint of sonic flow velocity at the throat limits the mass flow and a shock takes place in the divergent section of the nozzle, thus introducing strong pressure losses that ultimately limit the engine power.

Sonic restrictors are being used in several motorsport championships in order to equalize the maximum power of the engines. Among the racing series that make use of air restrictors are the Formula 3, the Formula SAE, the FIA GT1 World Championship, Le Mans Series and several others. Sometimes sonic restrictors are also used in road applications for derating purposes, mainly in motorbike engines.

In restricted engines, a reliable model of the air induction system is of paramount importance, as the flow in the sonic restrictor has direct effects on power generation and fuel efficiency.

The challenge when modelling a converging diverging nozzle lies in the asymmetric behaviour of the flow before and after the shock, with equations for the subsonic flow being very different from the ones used for supersonic conditions.

If not implemented in an efficient way, such a physical problem could trigger in Dymola several events and non-linear iterations, making the model computationally expensive.

\section{The sonic restrictor model}

The sonic restrictor is modelled in Dymola as a component where steady momentum, continuity and energy balances are performed. It uses the fluid connectors from Modelica.Fluid (Casella, F. et al., 2006) which make it fully compatible with the Modelica Standard Library.

As in pipes, the pressures at inlet and outlet determine the mass flow rate, the flow goes from the higher to the lower pressure and a greater pressure difference gives a higher mass flow.

For a pressure drop weaker than the critical one, the flow accelerates in the converging section and decelerates in the diverging one isentropically.

If the pressure at the throat equals the critical one, the nozzle becomes choked and the sonic condition is reached (see Equation 1, where $p_{c}$ is the critical 
pressure and $p_{i}$ the inlet pressure). Being the speed of sound the speed of propagation of small disturbances, the Mach at throat cannot be higher than 1, as the flow upstream the throat does not receive any information about what is happening downstream.

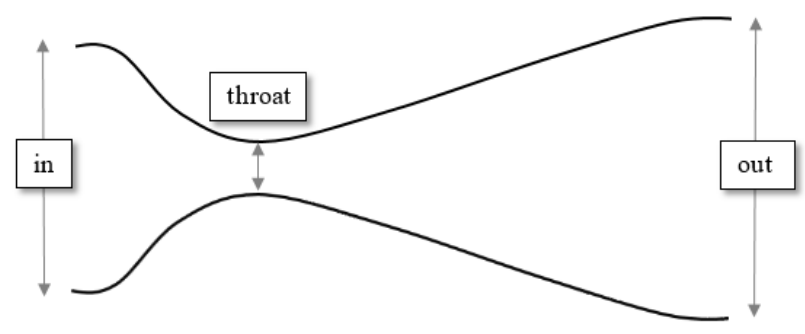

Figure 1. Sonic restrictor.

$$
\frac{p_{c}}{p_{i}}=\left(\frac{2}{\gamma+1}\right)^{\frac{\gamma}{\gamma-1}}
$$

If the pressure at the throat is further reduced, the mass flow at the throat is limited to the critical value, the flow becomes supersonic in the diverging section and a shock occurs. The critical mass flow rate can be found using Equation 2, where $p^{o}$ is the total pressure and $T^{o}$ the total temperature.

$$
\dot{m}_{c}=\frac{A \cdot p^{o}}{\sqrt{T^{o}}} \sqrt{\frac{\gamma}{R}}\left(\frac{\gamma+1}{2}\right)^{-\frac{\gamma+1}{2(\gamma-1)}}
$$

For air, with $\gamma=1.4$, the critical pressure ratio (given by Equation 1) is 0.528 , meaning that in a nozzle, the sonic condition is reached when the pressure at the throat is lower or equal to 0.528 times the pressure at inlet.

In all the other air ducts of the engine, the Mach is much lower than 1 and the continuity equation for a subsonic flow states that a decrease in area causes an increase in velocity. However, if the flow becomes supersonic, the flow behaviour changes and Equation 3 tells us that an increase in velocity is associated with an increase in area. In fact, the flow accelerates in the diverging section of a choked nozzle.

$$
\frac{d A}{A}=\left(M^{2}-1\right) \frac{d u}{u}
$$

In a choked nozzle, the flow accelerates isentropically from the inlet and its static pressure decreases maintaining a constant total pressure, until a shock occurs in the diverging section.

A shock is a discontinuity in the flow field across which the flow abruptly slows down from a supersonic to a subsonic speed while increasing the static pressure with huge associated viscous losses that reduce the total pressure.

The Mach numbers upstream (u) and downstream (d) of the shock are related by Equation 4 (Anderson J., 2002)

$$
M_{d}^{2}=\frac{1+\frac{\gamma-1}{2} M_{u}^{2}}{\gamma M_{u}^{2}-\frac{\gamma-1}{2}}
$$

This equation states that the further along the nozzle the shock occurs, the stronger it will be: as the Mach upstream increases above 1, the normal shock becomes stronger and $M_{d}$ becomes progressively less than 1, decreasing the total pressure of the flow leaving the sonic restrictor and entering the cylinders.

From a practical point of view, this means that the section in which the shock will occur will influence the total pressure of the flow entering in the cylinders.

The total pressures upstream and downstream the shock are linked by Equation 5 (Anderson J., 2002):

$$
\frac{p_{d}^{o}}{p_{u}^{o}}=\left[1+\frac{2 \gamma}{\gamma+1}\left(M_{u}{ }^{2}-1\right)\right]\left[\frac{1+\frac{\gamma-1}{2} M_{d}{ }^{2}}{1+\frac{\gamma-1}{2} M_{u}{ }^{2}}\right]^{\frac{\gamma}{\gamma-1}}
$$

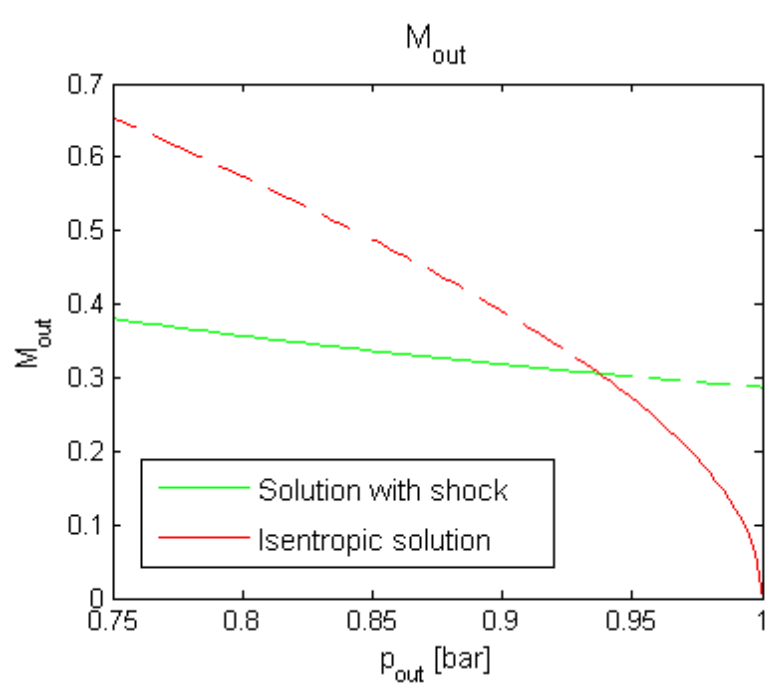

Figure 2. Discontinuity in the Mach number at the nozzle outlet going from a subsonic (red curve) to a supersonic (green curve) flow.

Figure 2 shows the Mach at the outlet of the sonic restrictor both when the sonic condition is not reached (red curve) and in case of shock (green curve). For a given inlet pressure, if the throat pressure is higher than the critical value, the flow remains isentropic, while if the throat pressure decreases further, the sonic condition is reached and the outlet Mach decreases drastically. 


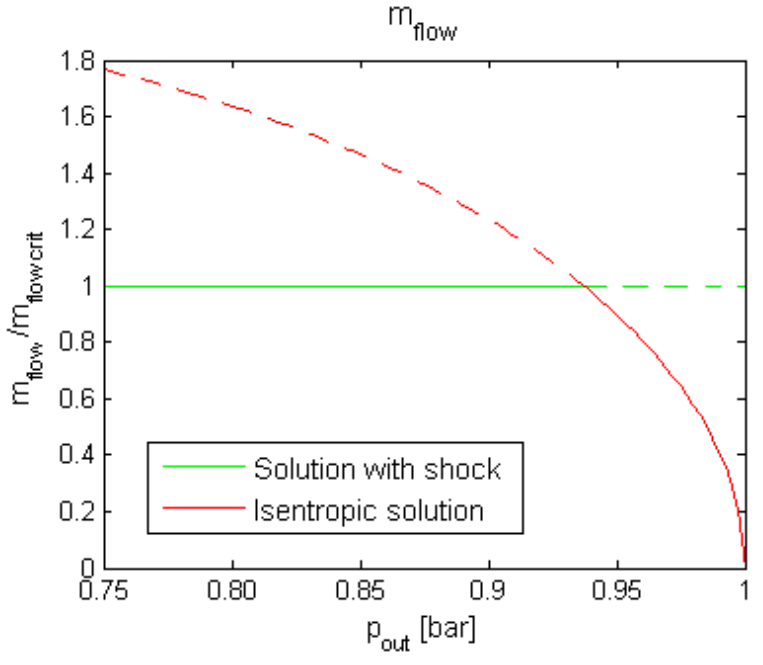

Figure 3. Discontinuity in the mass flow going from a subsonic (red curve) to a supersonic (green curve) flow.

Figure 3 shows the mass flow through the sonic restrictor for a subsonic flow (red curve) and for a supersonic flow (green curve).

The transition from the subsonic to the supersonic condition has been implemented in Dymola avoiding the use of if statements, as conditional expressions can trigger events. The mass flow rate through the sonic restrictor has been defined as the minimum value between the critical mass flow rate and the value from the isentropic solution using the operator min.

In case the sonic condition is not reached, the mass flow rate can be calculated using Equation 6:

$\dot{m}_{i s}=A_{\text {out }} \frac{p_{\text {in }}^{\circ}}{\sqrt{T^{\circ}}} \sqrt{\frac{\gamma}{R}} M_{\text {out }}\left(1+\frac{\gamma-1}{2} M_{\text {out }}^{2}\right)^{-\frac{\gamma+1}{2 \cdot(\gamma-1)}}$

For the chocked condition, the mass flow rate can be calculated using Equation 2.

In the same way, the Mach at the outlet of the sonic restrictor has been defined as the minimum value between the one reached in case of shock and the one in case of an isentropic solution, avoiding the use of conditional expressions.

The Mach at the outlet in case the sonic condition is not reached can be calculated using the definition of total pressure (Equation 7), assuming that $p_{\text {in }}^{\circ}=p_{\text {out }}^{\circ}$.

$$
M_{\text {out }, \text { is }}=\sqrt{\frac{2}{\gamma-1}\left(-1+\left(\frac{p_{\text {in }}^{\circ}}{p_{\text {out }}}\right)^{\frac{\gamma-1}{\gamma}}\right)}
$$

When the shock occurs, the Mach at the outlet can be calculated using Equation 8, that can be derived from Equations 2 and 6:

$$
\begin{gathered}
M_{\text {out }, \text { chocked }}=\sqrt{c_{1}+\sqrt{c_{2}+c_{3}\left(\frac{p_{\text {in }}^{\circ} \cdot A_{t}}{p_{\text {out }} \cdot A_{\text {out }}}\right)^{2}}} \\
c_{1}=-\frac{1}{\gamma-1} \\
c_{2}=\frac{1}{(\gamma-1)^{2}} \\
c_{3}=\frac{2}{\gamma-1}\left(\frac{2}{\gamma+1}\right)^{\frac{\gamma+1}{\gamma-1}}
\end{gathered}
$$

In this way, the solution will follow the continuous line of figures 2 and 3, discarding the dotted parts without using computationally expensive conditional expressions.

As far as the energy balance is concerned, the total temperature has been assumed to be constant between inlet and outlet.

\section{The engine model}

The sonic restrictor was integrated in an engine model developed using the Engines library (Picarelli, A. et al., 2009; Roberts, N. et al., 2013). A 0.6 L motorcyclederived four-cylinder naturally aspirated spark ignition engine was used.

A MVEM (Mean Value Engine Model) was used in place of a more detailed CAREM (Crank Angle Resolved Engine Model) in order to be able to focus on the effects of the sonic restrictor on the average air mass flow rate rather than on an oscillating value.

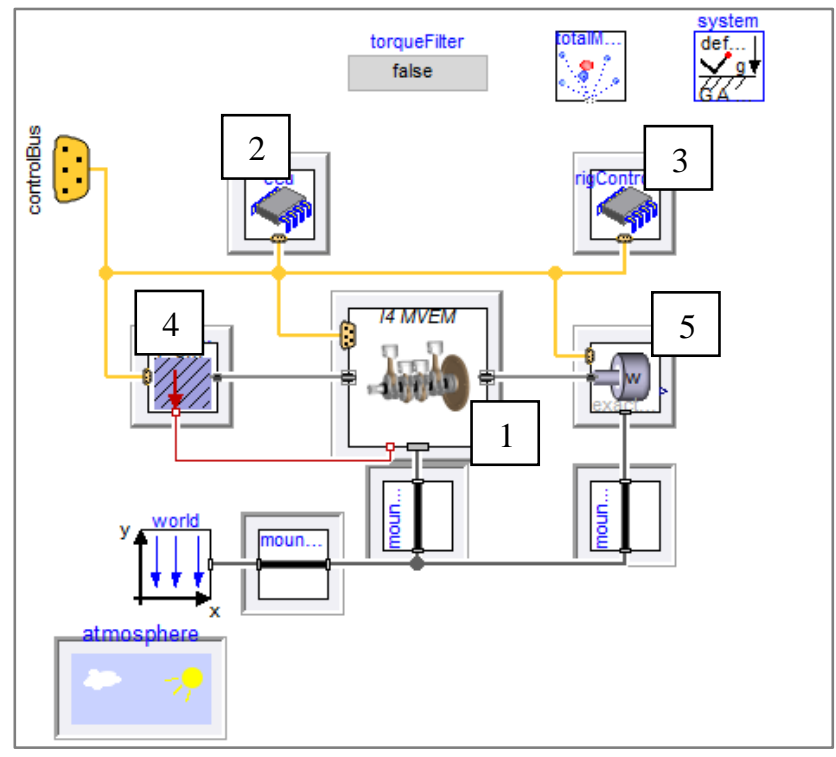

Figure 4. Engine test model: 1-Engine, 2-Engine Control Unit, 3-Rig Controller, 4-Engine coolant system, 5-Dyno. 
Figure 4 shows the test rig, where the engine is connected to a dyno (5) and controlled by the ECU (2). The engine is run on a dynamometer and controlled to ramp up from around $5000 \mathrm{rpm}$ to $11000 \mathrm{rpm}$ with wide open throttle in order to generate the full load curve. To achieve this, the rig controller (3) specifies the throttle opening.

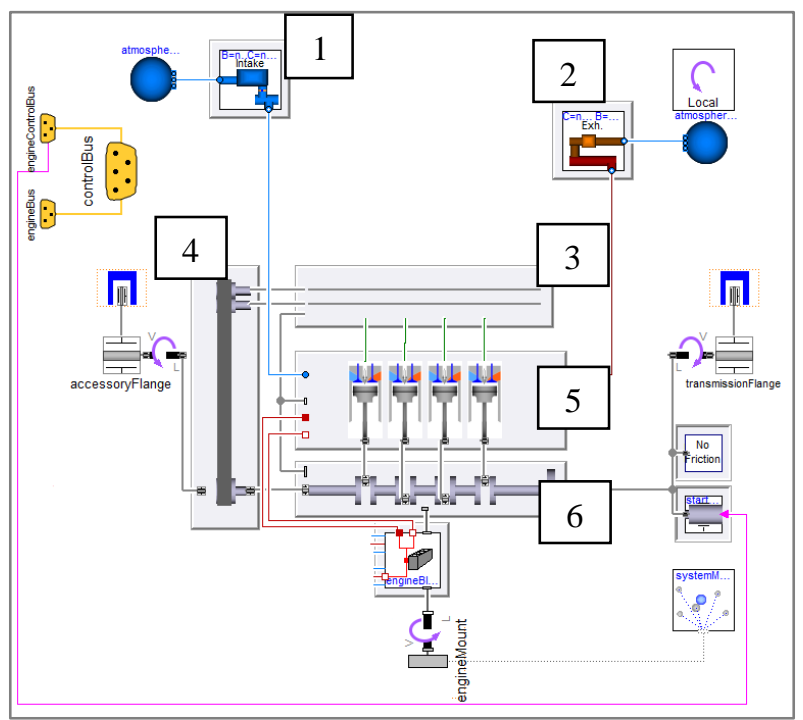

Figure 5. Engine model: 1-Intake, 2-Exhaust, 3-Camshaft 4-Timing belt, 5-Cylinder block, 6-Crankshaft.

Figure 5 shows the engine model, with the intake system (1), the exhaust system (2), the camshaft (3), the timing belt (4), the cylinder block (5) and the crankshaft (6).

Having used a MVEM in place of a CAREM, the camshaft and the timing belt models are empty, but they can be replaced with detailed models in case a CAREM engine is used.

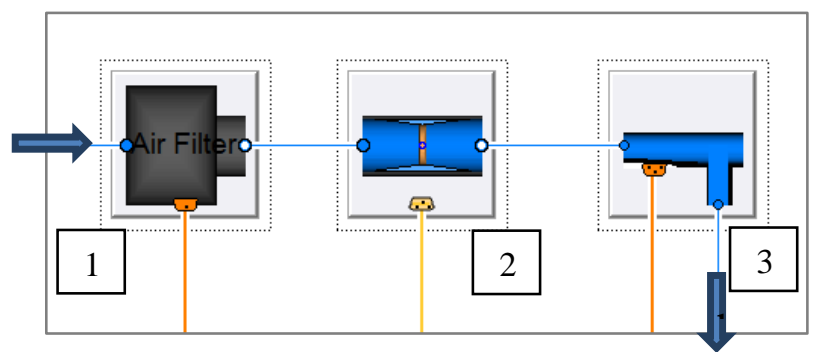

Figure 6. Intake model: 1-Air filter, 2-Throttle, 3-Intake manifold with sonic restrictor.

The intake system is shown in Figure 6 and consists of:

- The air filter (1) modelled with a pressure loss characteristic curve

- The throttle (2), modelled with an orifice also capable of modelling the choked condition. If the throttle is almost closed, the pressure ratio across it can be higher than the critical value $(0.528)$ and the choked condition can be reached. Also in this case, in the same way as for the sonic restrictor, the air flow rate at a given throttle position will be independent of manifold pressure and engine speed.

Having tested the engine at WOT (wide open throttle), there is no risk that the flow could become choked in the throttle, influencing the flow in the sonic restrictor.

- The intake manifold (3), containing the sonic restrictor and the plenum volume.

The sonic restrictor was placed after the throttle and before the plenum, as shown in Figure 7.

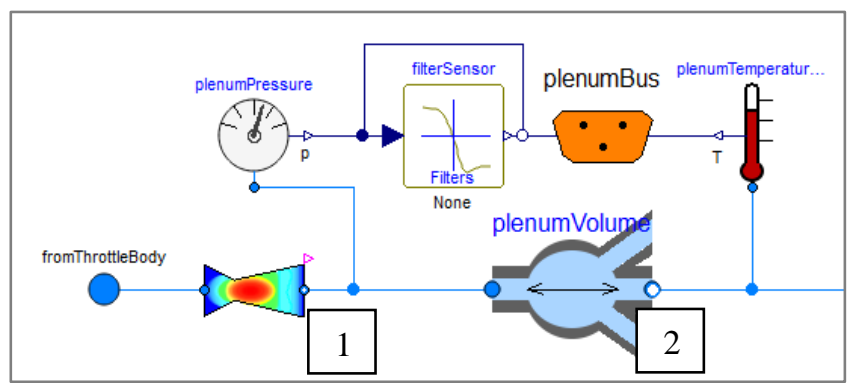

Figure 7. Intake manifold model: 1-Sonic restrictor, 2Plenum.

To compute the cycle-averaged torque, the Mean Value combustion model uses IMEP maps where the output is a function of engine speed and plenum pressure, with corrections for air fuel ratio, spark timing and cam timing. It's clear that, by influencing the plenum pressure, the sonic restrictor can yield a different engine torque characteristic.

The mass flow rate through the engine is calculated using Equation 9, as a function of intake air temperature, engine speed and plenum pressure (Hendricks et al., 1996).

$$
\dot{m}(n, p)=\frac{V_{d}}{120 R T}\left(s_{i} \cdot p_{i}+y_{i}\right) \frac{n}{1000}
$$

Where $n$ is the engine speed [rpm], $V_{d}$ the volumetric displacement of each cylinder $\left[\mathrm{m}^{3}\right], p_{i}$ the intake manifold pressure, $R$ the specific air gas constant $[\mathrm{J} / \mathrm{Kg} / \mathrm{K}]$ and $T$ the fluid temperature $[\mathrm{K}]$.

The coefficients $s_{i}$ and $y_{i}$ are function of speed and are provided in tabular format using experimental data. 


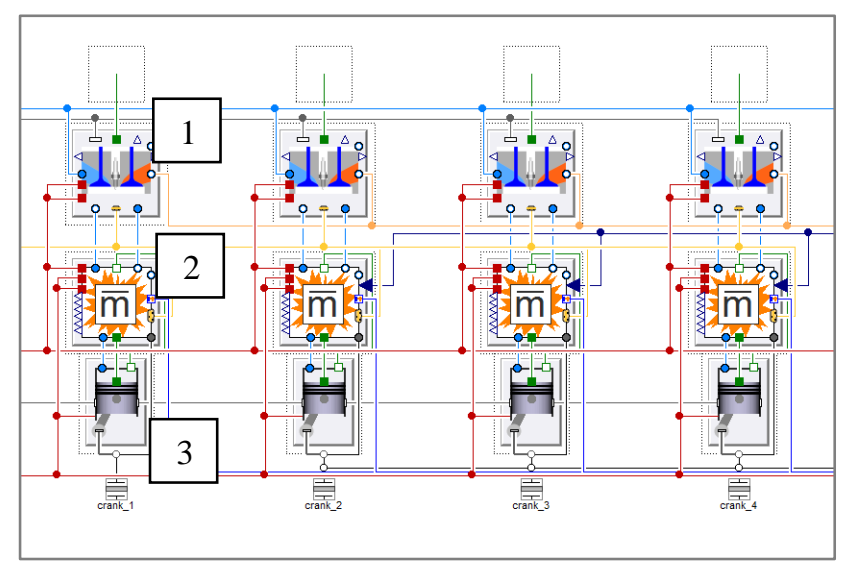

Figure 8. Cylinder block: 1- Piston head, 2-Combustion block, 3-Piston mechanism.

\section{Results}

The sonic restrictor model was integrated on a $0.6 \mathrm{~L}$ four-cylinder naturally aspirated spark ignition engine in order to analyse engine power and torque in case of choked flow.

Three different sonic restrictor throat areas were tested, with a throat diameter ranging from $20 \mathrm{~mm}$ to $25 \mathrm{~mm}$, increasing the throat area in each test by $25 \%$.

The results are shown in the following plots where At represents the case with a throat diameter of 22.4 $\mathrm{mm}, 0.75$ At the case with a throat area $25 \%$ smaller (throat diameter: $20 \mathrm{~mm}$ ) and $1.25 \mathrm{At}$ with a throat area 25\% larger (throat diameter: $25 \mathrm{~mm}$ ).

The inlet area has always been assumed to be the same as the outlet one.

In all the three cases, the engine was run at WOT from 5500 to $10500 \mathrm{rpm}$.

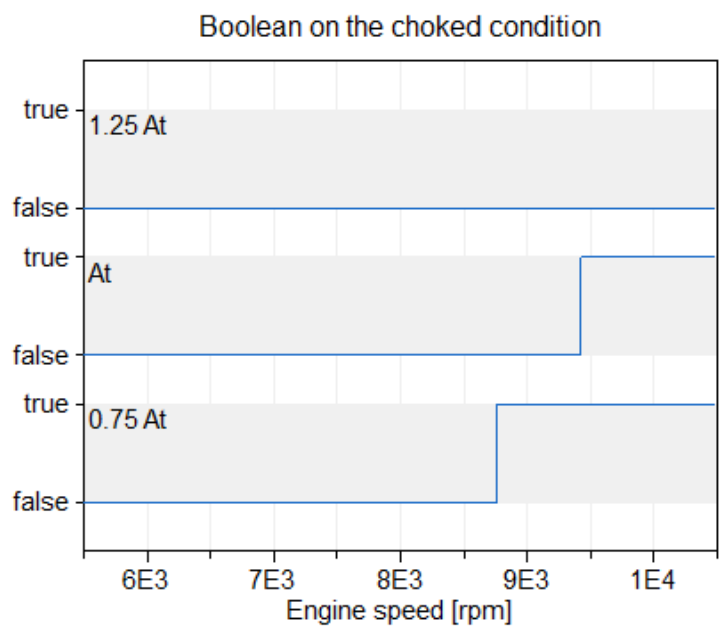

Figure 9. Boolean on the choked condition, true means that the restrictor is choked.
First of all, Figure 9 shows that in two of the 3 analysed cases the sonic condition was reached, while for the largest throat area (1.25 At) the flow remained always subsonic.

For a throat diameter of $20 \mathrm{~mm}(0.75 \mathrm{At})$, the choked condition was reached at $8760 \mathrm{rpm}$, while for a throat area $25 \%$ larger the choked flow was reached at $9450 \mathrm{rpm}$ (a speed around 8\% higher).
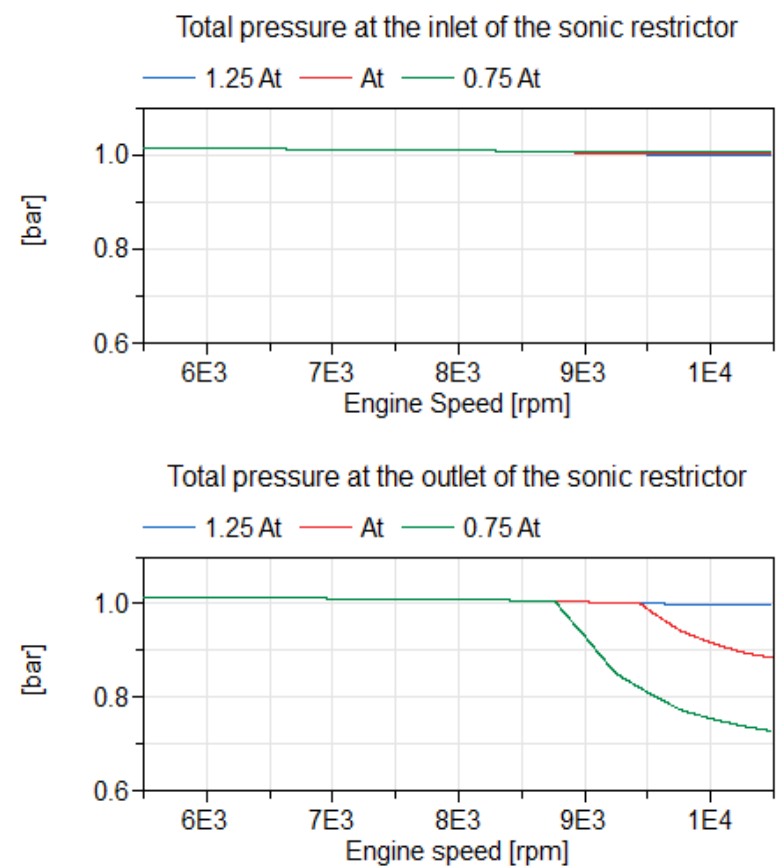

Figure 10. Total pressure at the inlet and the outlet of the sonic restrictor.

In the case of the largest throat area $1.25 \mathrm{At}$, the flow through the nozzle was isentropic and the total pressure across the sonic restrictor remained constant as shown in Figure 10, where the total pressures at the inlet and outlet of the sonic restrictor are plotted.

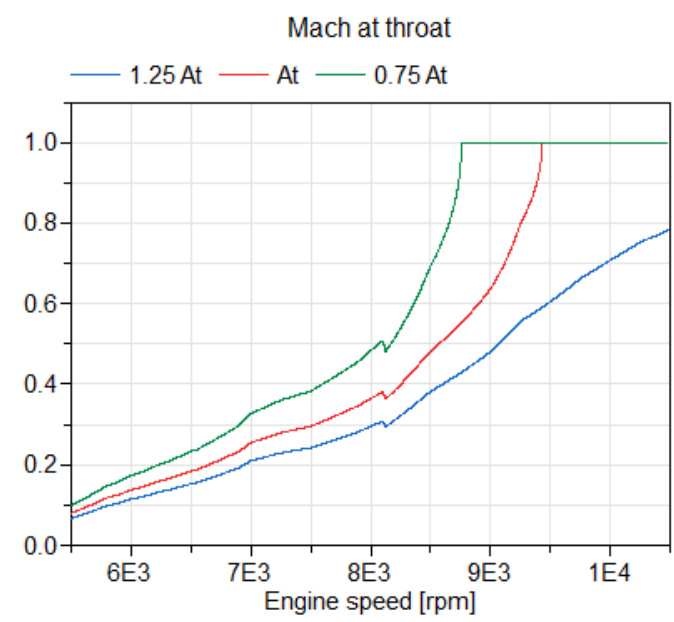

Figure 11. Mach at the sonic restrictor throat. 
The Mach at throat reached 0.8 at $10500 \mathrm{rpm}$, the engine torque, the engine power and the engine air mass flow rate followed the same trends as in a nonrestricted engine.

The engine torque reached its maximum at around $9000 \mathrm{rpm}$, the engine power reached its maximum at around 10000 . At $10500 \mathrm{rpm}$ the engine torque was already decreasing relatively steeply, while the engine power had just started to decline.

The mass flow rate increased following the engine speed ramp, as shown in Figure 14.

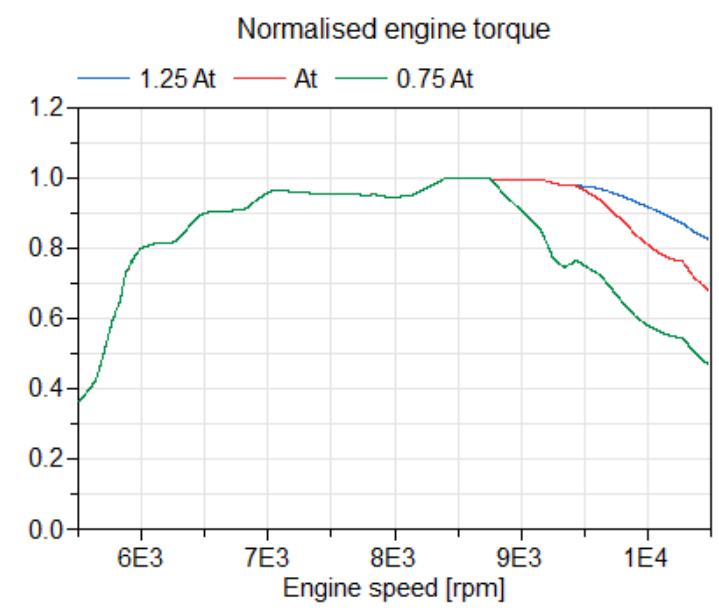

Figure 12. Normalised engine torque.

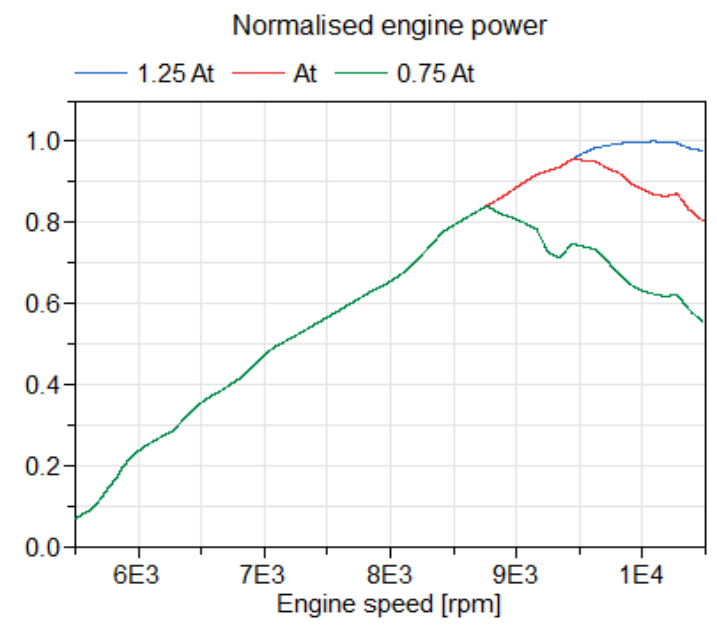

Figure 13. Normalised engine power.

For a throat area At, the sonic condition was reached at $9450 \mathrm{rpm}$, as shown in Figure 9.

Seemingly surprisingly, both the engine torque and the engine power decreased substantially at higher speeds (by around 18\% with respect to the non-choked condition at $10500 \mathrm{rpm})$. This happens because of the sonic restrictor losses associated to the shock. As the static pressure required by the engine downstream the sonic restrictor decreases, the nozzle needs a stronger shock to keep a constant mass flow, and the stronger shock corresponds to increased total pressure losses, as shown in the total pressure chart in Figure 10.

After the sonic speed was reached at throat, the mass flow rate was limited to the choked value and at 10500 rpm the mass flow rate was $13 \%$ lower than in the nonchoked case.

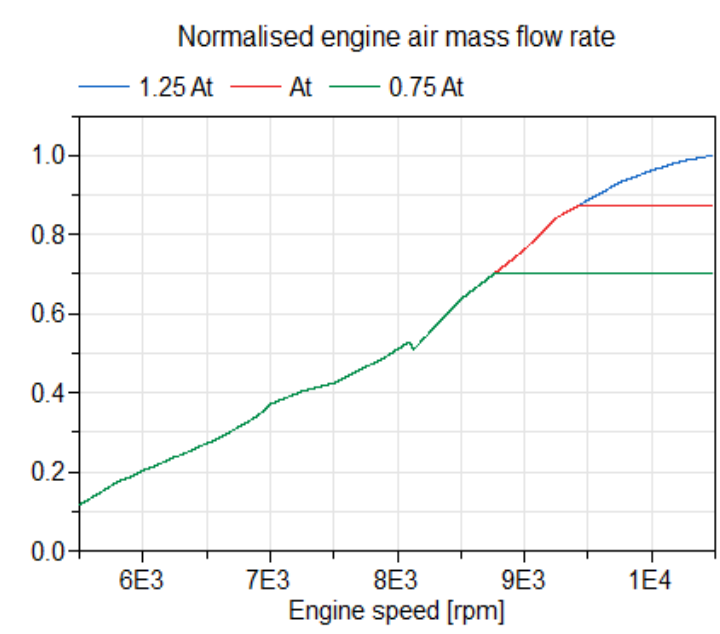

Figure 14. Normalised engine air mass flow rate.

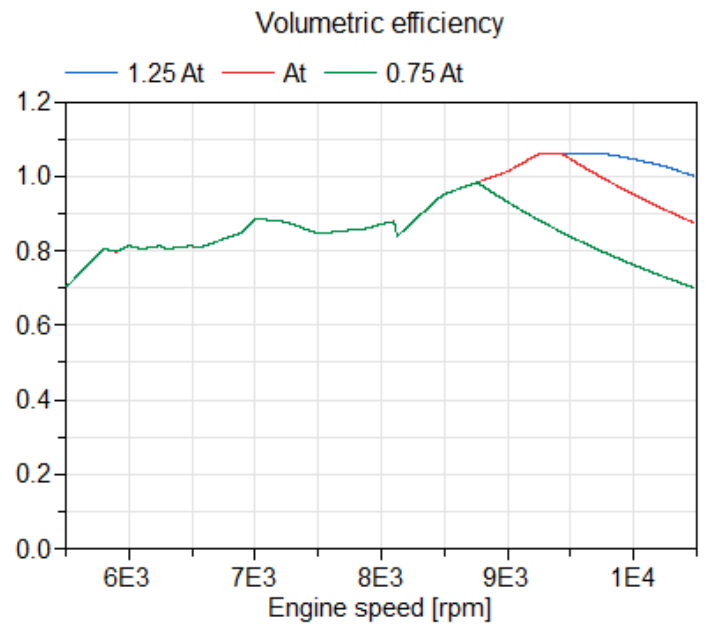

Figure 15. Volumetric efficiency.

By reducing the throat area a further $25 \%$, the simulations showed that the shock was reached at a lower engine speed (8760 rpm).

An important result to outline is that the shock was stronger in case of a smaller throat area, as shown by the greater total pressure drop in Figure 10 (from 1 bar to 0.73 bar at $10500 \mathrm{rpm}$ ).

At $10500 \mathrm{rpm}$ both the engine torque and the engine power were around $40 \%$ lower than in the case without shock.

For the same speed, the engine air mass flow rate was around 30\% less than in the case without shock. 
The drop in efficiency and power for the smallest throat area is clear also from Figure 15, where the volumetric efficiency is plotted.

The case with the smallest throat area shows clearly that the engine should not operate at speeds much higher than the one at which the sonic condition is reached. This suggests that the rev limiter should be set not far from the engine speed at which the air flow through the sonic restrictor becomes choked.

Furthermore, for a given displacement, engines with a higher torque at lower rotational speeds are likely to produce a higher power before the sonic restrictor becomes choked, thus bringing an advantage over ones optimised for higher regimes.

\section{Conclusions}

In this paper a sonic restrictor was integrated in an engine model to analyse the effect of choked flow through a nozzle on the engine mass flow rate, engine torque and engine power. Three cases with decreasing throat areas were analysed to assess the effect of the throat diameter on the shock intensity.

The full load curve showed that a considerable torque and power drop was reached after the choked condition, highlighting the need of limiting the maximum engine speed around the one at which the nozzle starts to be choked.

The study shows how Dymola can be used to analytically solve the fluid mechanics in engines. Of course, a quasi-1D code cannot solve phenomena such as flow separation and boundary layer development, but it can solve the shock and the compressible chocked flow, making it a good starting point for testing and development of restricted engines.

\section{References}

Casella F., Otter M., Proelss K., Richter C., Tummescheit H., The Modelica Fluid and Media library for modeling of incompressible and compressible thermo-fluid pipe networks, Proceedings of the 5th Int. Modelica Conference, Vienna, 2006.

Anderson J., Modern Compressible Flow: With Historical Perspective (Aeronautical \& Aerospace Engineering), McGraw-Hill Education; 3rd edition, 1 Aug. 2002.

Hendricks, E., Chevalier, A., Jensen, M., Sorenson, S. et al., Modelling of the Intake Manifold Filling Dynamics, SAE Technical Paper 960037, 1996, doi:10.4271/960037.

Picarelli, A., Dempsey M., Investigating the multibody dynamics of the complete powertrain system, Proceedings 7th Modelica Conference, Como, Italy, 2009. doi: 10.3384/ecp09430085

Roberts, N., Dempsey M., Picarelli A., Detailed Powertrain Dynamics Modelling in Dymola - Modelica, IFAC Proceedings Volumes, 2013, doi: 10.3182/20130904-4-JP2042.00111 